\title{
Determination of benzene in beverages by solid-phase microextraction and gas chromatography
}

\author{
André B. Sanchez', Dilma Budziak², Edmar Martendal ${ }^{3}$, Eduardo Carasek ${ }^{1 *}$ \\ ${ }^{1}$ Departamento de Química, Universidade Federal de Santa Catarina - UFSC, \\ Cep 88040-900, Florianópolis, SC, Brasil \\ ${ }^{2}$ Universidade Federal de Santa Catarina - UFSC, Campus Curitibanos, Cep 89520-000, Florianópolis, SC, Brasil \\ ${ }^{3}$ Departamento de Química, Universidade do Estado de Santa Catarina - UDESC, Cep 89219-710, Joinville, SC, Brasil \\ e-mail: eduardo.carasek@ufsc.br
}

\section{Abstract}

In this study, a simple and fast method was developed for the analysis of benzene in beverage samples using headspace solid-phase microextraction coupled to gas chromatography (HS-SPME-GC). The influence of factors such as extraction temperature, extraction time and addition of sodium chloride on extraction yield was studied through a multivariate experimental design. Satisfactory recoveries $(\geq 73 \%)$ and precision, calculated as relative standard deviations (RSD $\leq 9.1 \%$ ), were obtained. The limit of detection (LOD) of $0.2 \mu \mathrm{g} \mathrm{L}{ }^{-1}$ was achieved for benzene along with a wide linear range of concentration. The applicability of the proposed method was demonstrated for real samples including soft-drink, juice and tea samples. Since no matrix effects were observed, quantification could readily be carried out by external calibration with standards prepared in deionized water.

Keywords

Benzene; beverages; SPME; multivariate optimization.

\section{Determinação de benzeno em bebidas por microextração em fase sólida e cromatografia gasosa}

\section{Resumo}

Neste estudo, foi desenvolvido um método simples e rápido para a determinação de benzeno em amostras de bebidas, utilizando a microextração em fase sólida no modo headspace e cromatografia gasosa (HS-SPME-GC). Otimização multivariada foi utilizada para determinar a influência da temperatura de extração, tempo de extração e adição de cloreto de sódio sobre o rendimento da extração. Recuperações satisfatórias $(\geq 73 \%)$ e precisão, calculado como desvio padrão relativo (RSD $\leq 9,1 \%$ ), foram obtidas. Limite de detecção (LOD) de $0,2 \mu \mathrm{g} \mathrm{L} \mathrm{L}^{-1}$ foi obtido para benzeno, bem como uma ampla faixa linear de concentração. O método desenvolvido foi aplicado em amostras reais de refrigerantes, sucos e chás. Como não foi observado efeito de matriz, a quantificação foi realizada por calibração externa utilizando soluções padrão preparadas em água deionizada.

Palavras-chave

Benzeno; bebidas; SPME; otimização multivariada. 


\section{Introduction}

Benzene is carcinogenic to humans and has been reported to cause leukemia and other blood-related disorders. The several possibilities for the intake of benzene include drinking water and food, both through contaminations from the environment ${ }^{[1]}$. Beverages, especially those containing benzoate salts and ascorbic acid, are potential sources of contamination with benzene due to the decarboxylation of benzoate by a hydroxyl radical. These reactions are catalyzed by trace levels of metal ions that reduce oxygen via reactions involving ascorbic acid to form hydroxyl radicals ${ }^{[2]}$. However, there are no legal limits for the contamination of beverages with benzene, and the maximum contaminant level established for drinking water can be used. The World Health Organization ${ }^{[1]}$ and the US Environmental Protection Agency ${ }^{[3]}$ established the limit for benzene in drinking water at 10 and $5 \mu \mathrm{g} \mathrm{L}^{-1}$, respectively. A more rigorous guideline is that of the European Council, which has fixed the limit for benzene in drinking water at

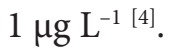

According to the maximum contaminant level for benzene in drinking water established by several agencies, it is expected that benzene exists in trace levels in beverages, thus an extraction/preconcentration technique is required. Techniques to quantify benzene in beverages make use of some form of headspace gas chromatography. Purge and trap ${ }^{[5,6]}$ and static headspace $^{[2,7-9]}$ approaches have been reported for extraction of benzene from several types of beverages. Fabietti et al. ${ }^{[6]}$, using the purge and trap technique, showed levels of benzene ranging from 1.1 to $2.6 \mu \mathrm{g} \mathrm{L^{-1 }}$ in a cola-based softdrink and from 2.4 to $3.6 \mu \mathrm{g} \mathrm{\textrm {L } ^ { - 1 }}$ in juice samples. Cao et al. ${ }^{[7]}$ used a static headspace approach resulting in a detection limit of $0.26 \mu \mathrm{g} \mathrm{L}^{-1}$, and the analysis of 124 soft-drink samples showed that only 6 samples had benzene concentrations over $5 \mu \mathrm{g} \mathrm{L}^{-1}$. On the other hand, solid-phase microextraction (SPME) which offers appropriate characteristics such as a sample preparation technique ${ }^{[10]}$, has been very little explored for the determination of benzene in beverages. Only one study to determine benzene in beverages conducted by a private laboratory used SPME in headspace mode (CAR/PDMS fiber) and gas chromatography - mass spectrometry (GC-MS) to monitor benzene in beverage samples ${ }^{[11]}$.

The main aim of this study was to explore the potential of the SPME technique for quantification of benzene in several kinds of beverage matrices. To reach this goal a full factorial design and a Doehlert matrix were used to optimize some variables involved in the HS-SPME procedure. The optimized method validation included determination of the limits of detection and quantification of the proposed method, linearity, repeatability, accuracy and linear range. To the best of our knowledge, this is the first time that HS-SPME procedure to determine benzene in beverage samples was conducted with diligent approach. Additionally, multivariate techniques were applied to optimize the proposed HS-SPME.

\section{Experimental}

\subsection{Instrumentation}

Chromatographic analysis for optimization and validation studies were performed on a Shimadzu GC-14B gas chromatograph (Kyoto, Japan), equipped with a split/splitless injector and a flame ionization detector. Chromatographic separations were carried out in an OV-5 capillary column (5\% phenyl-95\% polydimethylsiloxane, $30 \mathrm{~m} \times 0.25 \mathrm{~mm}, 0.25 \mu \mathrm{m}$ film thickness (OV Specialty Chemical, Marietta, 
$\mathrm{OH}$, USA). Ultrapure nitrogen was used as the carrier and make-up gas at initial flow-rate of 1.0

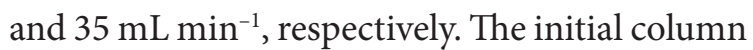
oven temperature was $40{ }^{\circ} \mathrm{C}$ ( 1 minute); subsequently increasing $10{ }^{\circ} \mathrm{C} \mathrm{min}^{-1}$ to $100{ }^{\circ} \mathrm{C}$ and $15^{\circ} \mathrm{C} \mathrm{min}^{-1}$ to $180^{\circ} \mathrm{C}$. The injector temperature was fixed at $300{ }^{\circ} \mathrm{C}$, except when the CW-DVB fiber was used because the manufacturer recommends a maximum temperature of $260{ }^{\circ} \mathrm{C}$. The detector temperature was fixed at $280^{\circ} \mathrm{C}$.

For the samples which could be quantified in gas chromatography - flame ionization detector (GC-FID) instrument, the identity of benzene was confirmed using a GC coupled with a mass spectrometer (Shimadzu GC-MS 2010 Plus). A Restek Rtx-5MS (5\% diphenyl-95\% dimethylpolysiloxane) capillary column $(30 \mathrm{~m} \times 0.25 \mathrm{~mm} \times$ $0.25 \mu \mathrm{m})$ was used for the GC separation (Bellefonte, PA). Helium was used as the carrier

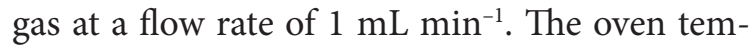
perature program and the injector temperature were the same as described previously under the GC section. The quadrupole mass detector was operated at $200{ }^{\circ} \mathrm{C}$ in the electron impact mode at $70 \mathrm{eV}$. The ion source temperature was set at $200{ }^{\circ} \mathrm{C}$, and the transfer line was set at $280^{\circ} \mathrm{C}$. The mass acquisition range was $40-100 \mathrm{~m} / \mathrm{z}$. The benzene peak was identified on the basis of its fragmentation pattern using the NIST Mass Spectral Search Program 05 (NIST, Washington, D.C., USA).

A Microquímica MQAMA 301 stirrer (Santa Catarina, Brazil) was used to stir the solutions and a Microquímica MQBTC 99-20 bath system was used to control the temperature.

\subsection{Chemicals and materials}

The standard stock solution of $100 \mathrm{mg} \mathrm{L}^{-1}$ benzene (Sigma-Aldrich, Milwaukee, WI, USA) was prepared in HPLC-grade methanol (Tedia, Fairfield, OH, USA). A working standard solu- tion of $50 \mu \mathrm{g} \mathrm{L} \mathrm{L}^{-1}$ was prepared in home-made orange juice to optimize the extraction procedure. Water obtained from a Milli-Q system (Millipore, Bedford, MA, USA) was used to prepare the standard solutions to construct external calibration curves. Sodium chloride (Vetec, Rio de Janeiro, Brazil) was used for the modification of the ionic strength of the samples.

The fibers investigated were polydimethylsiloxane (PDMS, $100 \mu \mathrm{m}$ ), divinylbenzenepolydimethylsiloxane (DVB-PDMS, $65 \mu \mathrm{m}$ ), carboxen-polydimethylsiloxane (CAR-PDMS, $75 \mu \mathrm{m}$ ), carbowax-divinylbenzene (CW-DVB, 65 $\mu \mathrm{m})$ and divinylbenzene-carboxen-polydimethylsiloxane (DVB-CAR-PDMS, 50/30 $\mu \mathrm{m}$ ), all purchased from Supelco (Bellefonte, PA, USA).

\subsection{Solid-phase microextraction procedures}

Firstly, each investigated SPME fiber was conditioned in the injector port of the GC according to the manufacturer's specifications. For the optimization step, as well as for validation of the method, $10 \mathrm{~mL}$ portions of spiked orange juice were hermetically sealed in $20 \mathrm{~mL}$ clear vials. In accordance with the experimental optimization design, $\mathrm{NaCl}$ was added to the spiked orange juice for the extractions. The samples were equilibrated during the incubation time of 5 minutes in a bath device at the appropriate temperature (selected according to the experimental design optimization procedure, described below). The fiber was immediately inserted into the GC injector and the analytes were thermally desorbed from the fiber for 5 minutes. No memory effects were observed.

\subsection{Optimization strategy}

The choice of the SPME fiber was carried out through univariate procedures obtained in triplicate. Each available fiber was used to extract 
benzene at $50 \mu \mathrm{g} \mathrm{L}^{-1}$ from $10 \mathrm{~mL}$ of orange juice containing $2.0 \mathrm{~g} \mathrm{NaCl}$ for 10 minutes at a temperature of $5^{\circ} \mathrm{C}$.

After the selection of the best SPME fiber, a full factorial design with one center point, including the variables ionic strength (1.0 and $3.0 \mathrm{~g} \mathrm{NaCl}$ in $10 \mathrm{~mL}$ of sample), temperature (2 and $10{ }^{\circ} \mathrm{C}$ ) and extraction time (10 and $20 \mathrm{~min}$ utes), was performed to evaluate the best experimental condition to extract benzene.

According to the results obtained in the experimental design, the extraction temperature and $\mathrm{NaCl}$ addition were the significant factors. A Doehlert matrix was used for optimization of the extraction temperature $\left(0 ; 2\right.$ and $\left.4{ }^{\circ} \mathrm{C}\right)$ and ionic strength $(1.5 ; 2.0 ; 2.5 ; 3.0$ and $3.5 \mathrm{~g}$ per $10 \mathrm{~mL}$ of sample), fixing the extraction time at 15 minutes. The experimental data were processed using the Statsoft Statistica 6.0 software.

\section{Results and discussion}

\subsection{Choice of fiber}

Initially, the values for the efficiency of benzene extraction from orange juice using five commercially available SPME fibers (PDMS, CAR-PDMS, DVB-CAR-PDMS, DVB-PDMS and CW-DVB) were compared. The experimental parameters fixed for this study were: extraction time of 10 minutes, extraction temperature of $5^{\circ} \mathrm{C}, 2 \mathrm{~g}$ of $\mathrm{NaCl}$ in $10 \mathrm{~mL}$ sample and $50 \mu \mathrm{g} \mathrm{L}$ of benzene. CAR-PDMS gave the best extraction efficiency with the highest chromatographic area for benzene; it was therefore selected to continue with the optimization. This results show that combining the absorption properties of the liquid polymer (PDMS) with the adsorption properties of porous particles (carboxen) in the extract phase promotes a high retention capacity.

\subsection{Optimization of extraction conditions}

A total of 11 experiments were carried out, including the three replicates at the central point, to determine the significance of each variable, as well as the influence of their interactions on the preconcentration procedure using the CARPDMS fiber, as shown in the Pareto chart in Figure 1.

As can be seen from the Pareto chart, the factors extraction temperature and $\mathrm{NaCl}$ addition are statistically significant at the $95 \%$ confidence level. The results obtained indicate that by increasing the $\mathrm{NaCl}$ amount and decreasing the sample temperature the recovery efficiency will improve. An increase in the extraction temperature increases the diffusion of the analytes through the fiber coating. However, as the sorption step is an exothermic process, an increase in the extraction temperature leads to a reduction in the partition coefficient, consequently reducing the amount of analyte extracted at equilibrium. Therefore, the extraction temperature has an antagonistic effect, and generally an optimum extraction temperature can be observed. Since benzene is a very volatile compound, a low sample temperature does not affect its volatility. Thus, a significant increase in the amount of benzene extracted was observed even at low sample temperature. Therefore, the thermodynamic effect was found to be more significant than the kinetic effect for the benzene extraction. On the other hand, the positive value obtained for the effect of salt addition indicates that the analytical response increases when the level changes from minimum to maximum. The addition of salt to the aqueous samples increases the ionic strength of the solutions and reduces the solubility of the analytes, as the aqueous media lowers its capacity of dissolving organic compounds, favoring 


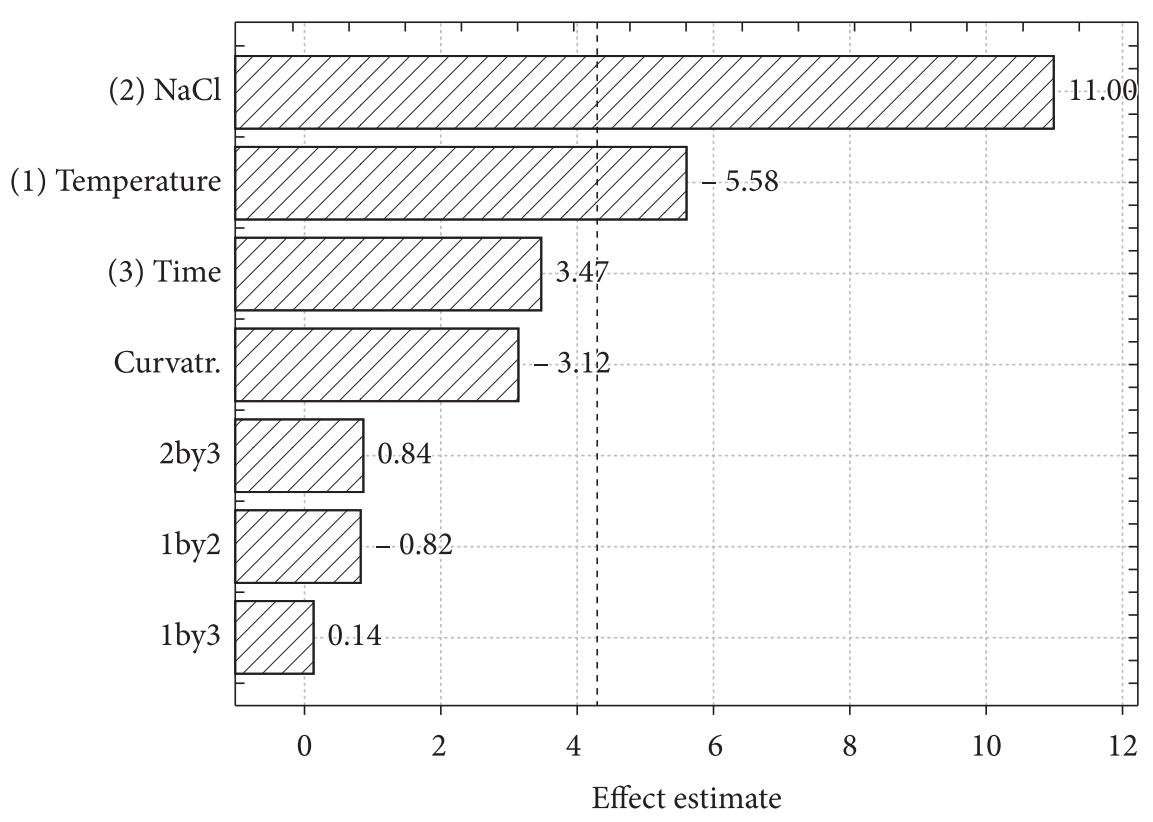

Figure 1 Pareto chart of standardized effects for the variables of the SPME procedure using the peak area as the analytical response. (1) extraction temperature, (2) $\mathrm{NaCl}$ addition, (3) extraction time, (1 by 2) interaction between extraction temperature and $\mathrm{NaCl}$ addition, ( 1 by 3 ) extraction temperature and time (2 by 3 ) extraction time and $\mathrm{NaCl}$ addition.

their partitioning between the sample and fiber coating $^{[12]}$.

In contrast, by considering the conditions set within the experimental domain, neither the extraction time nor the interaction between the variables were significant, and thus the extraction time was fixed at 15 minutes for all experiments (central point value).

\subsection{Doehlert design}

It was observed from the results of the factorial design that the variables extraction temperature and salt addition required a final optimization. Therefore, a Doehlert matrix was constructed with these variables. Seven experiments were carried out with levels of 0,2 and $4{ }^{\circ} \mathrm{C}$ and $1.5 ; 2.0 ; 2.5 ; 3.0$ and $3.5 \mathrm{~g}$ of $\mathrm{NaCl}$ for the extraction temperature and salt addition, respectively.
Figure 2 shows the response surface built for the extraction temperature and $\mathrm{NaCl}$ addition, maintaining an extraction time of 15 minutes. By analyzing the response surface, the set of SPME conditions, within the experimental domain, that generated the best extraction recovery for benzene, was visually determined. These conditions correspond to an extraction temperature of $0{ }^{\circ} \mathrm{C}$ and addition of $3.0 \mathrm{~g}$ of $\mathrm{NaCl}$. Experimental limitations did not allow lower extraction temperatures and the higher amount of $\mathrm{NaCl}$ added was close to the saturation of the solution.

\subsection{Validation of the method}

Table 1 shows the limits of detection (LOD) and quantification (LOQ), linear range, relative standard deviation (RSD) and correlation coefficient $(R)$ for the analysis of benzene in the orange juice matrix with the CAR-PDMS fiber under 
the optimized HS-SPME conditions. The limits of detection and quantification were calculated as three and ten times the standard deviation of the linear coefficient of the calibration curve divided by the slope of the calibration function, respectively. Good correlation coefficients $(R)$ were obtained, higher than 0.999 . The method showed an excellent precision, calculated as the relative standard deviation ( $n=6)$ using a natural orange juice spiked with 5 and $20 \mu g \mathrm{~L}^{-1}$ of benzene (Table 1).

\subsection{Application of the methodology to beverage samples}

The developed method was applied in the analysis of 9 commercial beverage samples purchased in Florianópolis - Brazil. All samples contained ascorbic acid and benzoic acid in their compositions, which could form benzene. These samples included soft-drinks, juices and teas ready for consumption, and concentrated juices. The concentrated juices were prepared in accordance with the information obtained from the product label before analysis. Benzene was quan-

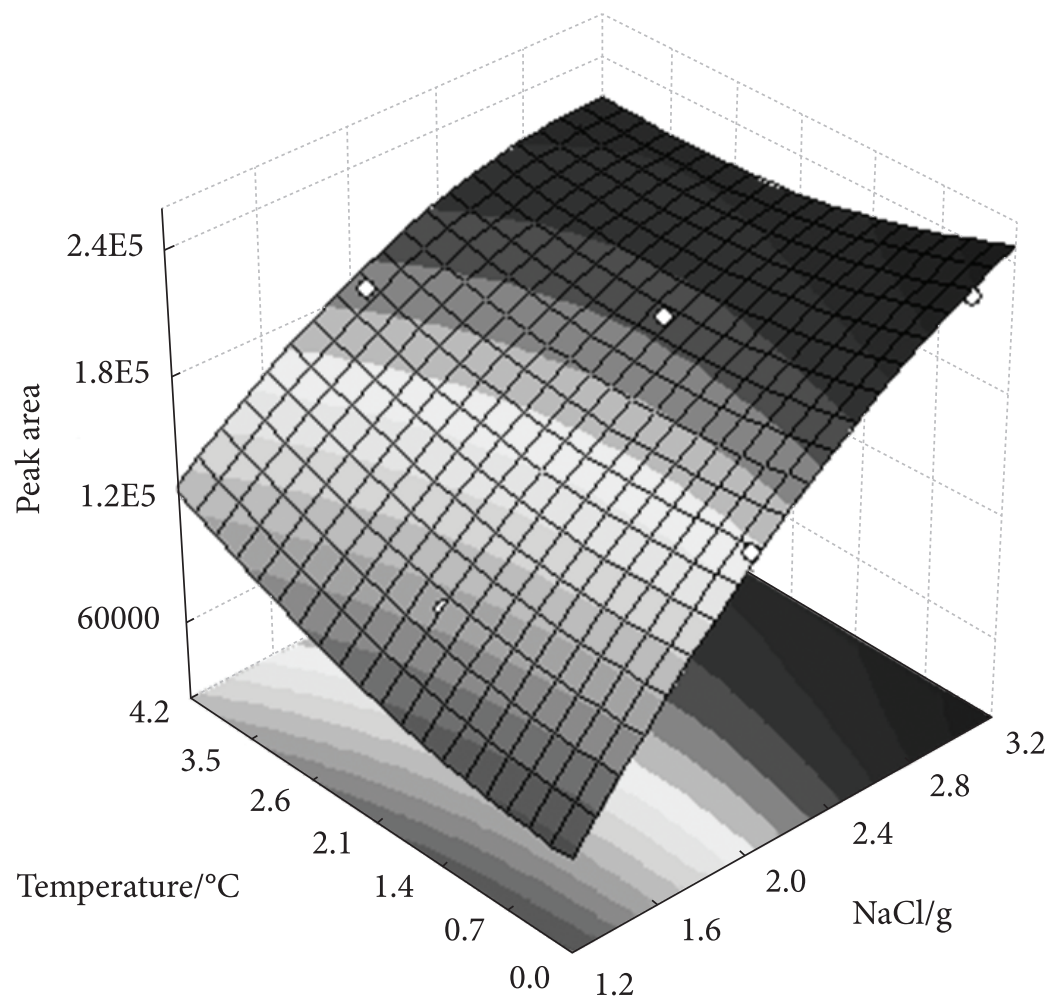

Figure 2 Response surface for optimization of extraction temperature and salt addition obtained from the Doehlert matrix.

Table 1 Linear range, correlation coefficients, and detection and quantification limits obtained for the proposed method.

\begin{tabular}{|c|c|c|c|c|}
\hline Linear range $/ \mu \mathrm{g} \mathrm{L}^{-1}$ & $\mathbf{R}$ & $\mathrm{LOD}^{a} / \mu \mathrm{g} \mathrm{L}^{-1}$ & $\mathrm{LOQ}^{\mathrm{b}} / \mu \mathrm{g} \mathrm{L}^{-1}$ & $\operatorname{RSD} \%(n=6)$ \\
\hline \multirow[t]{2}{*}{$0.5-50$} & 0.999 & 0.2 & 0.6 & $9.1\left(5 \mu \mathrm{g} \mathrm{L}^{-1}\right)$ \\
\hline & & & & $5.7\left(20 \mu \mathrm{g} \mathrm{L}^{-1}\right)$ \\
\hline
\end{tabular}

aLO; limit of detection. 'bOQ; limit of quantification. 
tified using the optimized procedure. To study possible interference effects, the slopes for an external analytical curve and a standard addition curve for each sample were compared, and the relative sensitivity was calculated. This procedure shows adequate relative sensitivities for all the samples (recoveries between 73 and 99\%), indicating that the sample matrix has little influence on the SPME method. Therefore, an external calibration curve can be used successfully for quantitative analysis, making the proposed method simpler and faster. The results can be observed in Table 2. In all the samples which benzene could be quantified, we performed a confirmatory study using the proposed method except we used a GC-MS instrument. All the samples analysed in GC-MS gave a positive identification of benzene, all with a similarity between obtained spectra and that from the library higher than $90 \%$. It should be also mentioned that for none of the samples analysed a coelution ocurred between flavor compounds and benzene peak, showing a satisfactory selectivity of the method.

As seen in Table 2, seven samples (78\%) contained quantifiable concentrations of benzene, of which 5 were above the European limit for benzene in drinking water of $1 \mu \mathrm{g} \mathrm{L}^{-1}$ and 4 samples were above the $5 \mu \mathrm{g} \mathrm{L} \mathrm{L}^{-1}$ US Environmental
Protection Agency maximum contaminant level for drinking water. Three of the samples even had a concentration higher than $10 \mu \mathrm{g} \mathrm{L}^{-1}$, thereby exceeding the action limit for benzene in drinking water of $10 \mu \mathrm{g} \mathrm{L}^{-1}$ proposed by the World Health Organization ${ }^{[1]}$.

Gardner \& Lawrence ${ }^{[2]}$ showed that hydroxyl radicals, generated by the metal catalyzed reduction of $\mathrm{O}_{2}$ and $\mathrm{H}_{2} \mathrm{O}_{2}$ by ascorbic acid, can attack benzoic acid to produce benzene. Under the experimental conditions that they obtained (reaction time of 15 minutes, reaction temperature of $25^{\circ} \mathrm{C}$, sample $\mathrm{pH}$ of 3.0, and benzoic acid, ascorbic acid, $\mathrm{H}_{2} \mathrm{O}_{2}$, and $\mathrm{Cu}^{2+}$ concentrations of $760,1400,360$ and $16 \mathrm{mg} \mathrm{L}^{-1}$, respectively) the benzene concentration was found to be around $2.0 \mu \mathrm{g} \mathrm{L}{ }^{-1}$. To verify the formation of benzene in beverages, we carried out an experiment using natural orange juice and adding benzoic acid and ascorbic acid in a concentration much closer to the real quantities found in commercial products. The natural orange juice was spiked with benzoic acid at a concentration of $100 \mathrm{mg} \mathrm{L}^{-1}$, ascorbic acid at a concentration of $20 \mathrm{mg} \mathrm{L}^{-1}$ and $\mathrm{Cu}^{2+}$ at a concentration of $100 \mu \mathrm{g} \mathrm{L}^{-1} \cdot \mathrm{H}_{2} \mathrm{O}_{2}$ was not added (as this substance is not added to any commercial beverage) and the sample $\mathrm{pH}$ was 3 . The prepared orange juice was storage at room

Table 2 Concentration and recovery values using standard addition and external calibration curve methods.

\begin{tabular}{|c|c|c|}
\hline Sample & Mean concentration $\pm \mathrm{SD} / \mu \mathrm{g} \mathrm{L}^{-1}$ & Recovery (\%) \\
\hline Cola-based soft drink & $0.8 \pm 0.2$ & 81.0 \\
\hline Citrus fruit juice & $<\mathrm{LOD}^{\mathrm{a}}$ & 82.4 \\
\hline Lemon juice & $0.8 \pm 0.3$ & 99.5 \\
\hline Isotonic juice & $1.2 \pm 0.7$ & 73.2 \\
\hline Tea 1 & $15.2 \pm 1.1$ & 94.0 \\
\hline Tea 2 & $12.6 \pm 1.5$ & 86.5 \\
\hline Tea 3 & $11.4 \pm 0.5$ & 77.3 \\
\hline Concentrated juice $1^{a}$ & $6.9 \pm 0.6$ & 92.3 \\
\hline Concentrated juice $2^{a}$ & $<\mathrm{LOD}^{\mathrm{b}}$ & 86.6 \\
\hline
\end{tabular}

aprepared in accordance with the information obtained from the product label before analysis. 'bOD; limit of detection. 
temperature and two portions of $10 \mathrm{~mL}$ were analyzed after: 30 minutes and 45 days. As in the case of Gardner \& Lawrence ${ }^{[2]}$, in the first analysis of this study no benzene was detected, but in the second analysis we detected a benzene concentration of $7.2 \mu \mathrm{g} \mathrm{L}^{-1}$, demonstrating the formation of benzene under real conditions found in industrialized beverages and confirming that the source of benzene found in the samples we analysed can be the decarboxylation of benzoic acid used in beverage fabrication.

\section{Conclusions}

The optimization of the variables using full factorial design and response surface methodologies was applied with success in the determination of benzene in beverages samples. The proposed method achieved excellent detection limits, relative standard deviation and accuracy. The results of this study demonstrate the applicability of the proposed method for determination of benzene concentrations below $1 \mu \mathrm{g} \mathrm{L} \mathrm{L}^{-1}$, that is, the ability to quantify benzene even for the European Council, which establishes the most rigorous guidelines for benzene in drinking water.

\section{Acknowledgements}

The authors are grateful to $\mathrm{CNPq}$ for their financial support.

\section{References}

1 World Health Organization - WHO. Guidelines for drinking-water quality. Available from: http://www. who.int/water_sanitation_health/dwq/gdwq0506.pdf.

2 Gardner LK, Lawrence GD. Benzene production from decarboxylation of benzoic acid in the presence of ascorbic acid and a transition metal catalyst. Journal
Agriculture Food Chemistry 1993; 40:693-695. http:// dx.doi.org/10.1021/jf00029a001

3 U.S. Environmental Protection Agenc - EPA. Consumer Factsheet on: BENZENE. Available from: http://www.epa.gov/safewater/dwh/c-voc/benzene. html.

4 European Communities. Council Directive 98/83/EC, of 03 november 1998. Official Journal of the European Communities, Nov. 1998. Available from: http:// europa.eu.int/eur-lex/pri/en/oj/dat/1998/1_330/ 1_33019981205en00320054.pdf.

5 McNeal TP, Nyman PJ, Diachenko GW, Hollifield HC. Survey of benzene in foods by using headspace concentration techniques and capillary gas chromatography. Journal of AOAC International 1993; 76(6):1213-1219. PMid:8286958.

6 Fabietti F, Delise M, Bocca AP. Investigation into the benzene and toluene content of soft drinks. Food Control 2001; 12(8):505-509. http://dx.doi. org/10.1016/S0956-7135(01)00041-X

7 Cao XL, Casey V, Seaman S, Tague B, Becalski A. Determination of benzene in soft drinks and other beverages by isotope dilution headspace gas chromatography/mass spectrometry. Journal of AOAC International 2007; 90(2):479-484.

8 Nyman PJ, Diachenko GW, Perfetti GA, Macneal TP, Hiatt MH, Morehouse KM. Survey results of benzene in soft drinks and other beverages by headspace gas chromatography/mass spectrometry. Journal of Agriculture Food Chemistry 2008; 56(2):571-576. http://dx.doi.org/ 10.1021/jf0724791

9 Poucke CV, Detavernier C, Bocxlaer JFV, Vermeylen $\mathrm{R}$, Peteghem CV. Monitoring the benzene contents in soft drinks using headspace gas chromatographymass spectrometry: A survey of the situation on the Belgian market. Journal of Agriculture Food Chemistry 2008; 56(12):4504-4510. http://dx.doi. org/10.1021/jf072580q

10 Budziak D, Martendal E, Carasek E. Preparation and application of NiTi alloy coated with $\mathrm{ZrO} 2$ as a new fiber for solid-phase microextraction. Journal of Chromatography A 2007; 1164(1-2):18-24. http:// dx.doi.org/10.1016/j.chroma.2007.07.001

11 Food Survey Information Sheets. Survey of benzene in soft drinks. 2006. Available from: http://www.food.gov. uk/multimedia/pdfs/fsis0606.pdf.

12 Pawliszyn J. Solid Phase Microextraction: Teory and practice. Wiley-VCH; 1997. 